\title{
SIX-PHASE BIDIRECTIONAL RECTIFIER: MODELLING, CONTROL AND EXPERIMENTAL RESULTS IN $\alpha \beta$ REFERENCE FRAME
}

\author{
Cesar A. Arbugeri, Samir A. Mussa \\ Universidade Federal de Santa Catarina-UFSC, Departamento de Engenharia Elétrica e Eletrônica-EEL \\ Instituto de Eletrônica de Potência - INEP, Florianópolis - SC, Brasil \\ e-mail: cesar.a@inep.ufsc.br, telles@inep.ufsc.br, samir@inep.ufsc.br
}

\begin{abstract}
Poly-phase machines have been used for many years in motor drives and more recently in wind power generation. In wind generation the most common poly-phase system is the six-phase, which consists of a dual three-phase system, shifted by 30 electrical degrees from each other and with no neutral connection. Typically, this system employs a twelve-pulse diode rectifier to convert AC to DC voltages. Better results can be achieved employing an active rectifier, since it can provide lower distortion in generator currents and regulated output voltage. However, the dynamic and stationary model of this converter are not reported in the literature, taking that into account, this paper proposes a six-phase active rectifier topology for a dual three-phase system. A stationary frame reference for six-phase system is applied to obtain the converter dynamic model in the $\alpha \beta$ coordinates and thus a control strategy is proposed in this frame reference. The proposed topology and control strategy were experimentally verified with a 12 kW prototype. The results were appropriated, providing a regulated output voltage, an input current with reduced harmonic distortion and thus high power factor.
\end{abstract}

Keywords - Control, PFC, Rectifier, Six-phase, Stationary Frame Reference.

\section{INTRODUCTION}

Poly-phase machines are a viable solution for a wide range of applications, not only in motor drives, but also in electrical generation. Due to the employment of power electronics in most of the motor drives and renewable energy, the connection of these poly-phase machines with three-phase mains are not a restriction. The use of poly-phase systems provides several advantages, especially in terms of fault tolerance.

Historically, the use of diode and thyristor rectifiers brought the concern about power factor and problems caused in the electrical grid, due to high Total Harmonic Distortion (THD) of the currents drained from the mains. However, the creation of international standards (for example IEC 1000-3-2 and IEEE 519) has imposed firm restrictions to current harmonic distortion in modern rectifiers, which narrows the use of passive rectifier.

This fact stimulated the study, development and improvement of several topologies in the field of power electronics, while aiming to provide power factor correction.

Manuscript received 17/08/2018; first revision 17/09/2018; accepted for publication 14/12/2018, by recommendation of Editor Marcello Mezaroba. http://dx.doi.org/10.18618/REP.2019.1.0032
Some works, such as [1]-[6], proposed power converters employing diode bridges with some sort of active control, and thus the boost type converters became the most popular topology for operation as power-factor correction (PFC) converter in single-phase systems.

On the other hand, in three-phase PFC rectifier the most popular topology is the two-level voltage-source converter (2L-VSC), which provides a reduced harmonic distortion in the input current and a regulated output voltage. This topology is widely studied in the literature [7]-[9], and several control approaches were proposed to ensure a proper operation as a rectifier, the most common strategies being the classical control in the stationary frame reference ( $\alpha \beta$ coordinates) or in the synchronous reference frame ( $d q$ coordinates).

Poly-phase systems have become more relevant and more employed, initially in motor drives applications, aiming a better performance in high power applications, being usual system of 5, 6, 9 and 12 phases, applied in traction applications [10]-[13]. And more recently in power generation, especially in wind systems [14]-[19]. In conventional six-phase generation, twelve-pulse diode rectifiers are employed in the ac-dc voltage conversion, and this solution has been showing good results. Nevertheless, the use of active rectifiers that provide a lower distortion on generator currents and a regulated output voltage might become more attractive.

The work [20] presented the basic operation of a six phase active rectifier validating the models and control with numeric simulations, which are experimentally validated in this paper, thoroughly corroborating the simulation results. Besides, a more precise model for the output voltage transfer function is obtained through the use of the converter's the power equations, and a static analysis of the converter is presented providing project criteria for the selection of passives and active components.

The objective of this paper is to propose a six-phase active rectifier topology, as well as models and a control strategy in stationary frame reference which aims to provide an input current with reduced harmonic content and regulate the output voltage. The proposed methodology can be applied not only in six-phase generation systems, but also in motor drives employing a back-to-back configuration. The remainder of this paper is organized as follows: the converter basic operation is presented in Section II, describing the topology and modulation strategy. The converter dynamic model in a stationary reference frame is deducted in the Section III. In Section IV are presented the static analysis and an example of project for the converter, including a control proposal. The models and the converter operations are validated by a prototype and the results are shown in Section V. Conclusions 


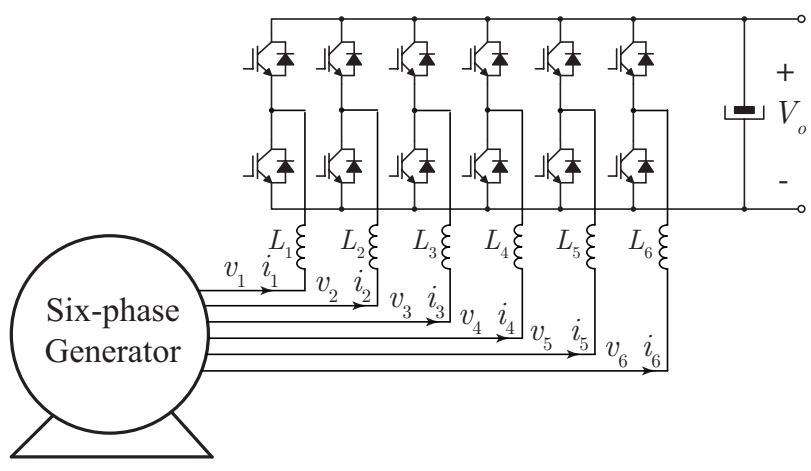

Fig. 1. Six-phase two-level voltage-source active PWM rectifier topology.

are presented in Section VI.

\section{SIX-PHASE TWO-LEVELS VOLTAGE SOURCE CONVERTER}

This section presents the six-phase two-levels voltagesource converter and its principle of operation.

\section{A. Six-Phase Rectifier Topology and Operation}

The rectifier is a two-level voltage-source converter topology, as presented in the Figure 1. Each leg of the converter is composed by two active switches driven by complementary gate signals. The converter is current bidirectional fed by a six-phase source, e.g., a dual threephase generator or a wye/delta-wye transformer. In this paper, this source consists of a dual three-phase system where one is shifted by 30 electrical degrees from the other and without a neutral connection. This neutral disconnection is due to the machine windings, which are connected in two sets of three, avoiding common mode current circulation and generating the six-phase system as a dual three-phase system.

\section{B. Modulator Scheme}

The operation of the six-phase converter is similar to a three-phase two-level converter. The main difference is the phase quantity. The modulation scheme for the converter consists of a bipolar PWM - the modulator signal is generated by the controllers and compared with a triangular carrier, generating the gate signal. This signal controls the upper switch, while the lower switch is controlled by its complementary.

Other modulators can also be employed, such as a space vector modulator. However, choosing the suitable vectors and its application time is very complex, mostly due to the high number of vectors and the higher dimension of the system model. Since this work is focused in the converter modelling and control, a simple modulation strategy was adopted.

\section{STATIONARY REFERENCE FRAME CONVERTER MODELLING}

The dual three-phase system voltages are not independent, i.e, there is a coupling among phases. However, the system models can be represented in stationary reference frame $(\alpha \beta)$ or synchronous reference frame $(d q)$. The advantage of employing the $d q$ transformation, is representing the voltage and current fundamentals by constant values. Nonetheless, there is a coupling between the axes in this reference frame. In this paper, an $\alpha \beta$ transformation is employed due the decoupling provided among phases.

At a first moment, the stationary frame transformation is shown, transforming the six-phase reference frame into two $\alpha \beta$ planes and two common mode voltages. Afterwards, the linearized models for the input current and the output voltage transfer functions are presented, which are then used for the controller design.

\section{A. Alpha Beta Stationary Frame Reference Transformation}

This linear transformation was initially proposed in [21] for three-phase systems and in a second moment generalized for poly-phase systems in [22], and consists in a transformation matrix exposed in (1). This transformation is proposed to decompose the original six-dimensional rectifier into three two-dimensional orthogonal subspaces $\left(\alpha_{1}, \beta_{1}\right),\left(\alpha_{2}, \beta_{2}\right)$ and $\left(0_{1}, 0_{2}\right)$. The fundamental components of the rectifier and the harmonics of order $k=12 n \pm 1, n=\{1,2,3, \ldots\}$ are mapped in the $\left(\alpha_{1}, \beta_{1}\right)$ subspace. The harmonics of order $k=6 n \pm 1$, $n=\{1,3,5, \ldots\}$ are mapped in the $\left(\alpha_{2}, \beta_{2}\right)$ subspace and the zero-sequence components are mapped in the $\left(0_{1}, 0_{2}\right)$ subspace [23].

$$
\left[\begin{array}{l}
v_{\alpha 1} \\
v_{\beta 1} \\
v_{\alpha 2} \\
v_{\beta 2} \\
v_{01} \\
v_{02}
\end{array}\right]=\frac{1}{\sqrt{3}}\left[\begin{array}{cccccc}
1 & -\frac{1}{2} & -\frac{1}{2} & \frac{\sqrt{3}}{2} & -\frac{\sqrt{3}}{2} & 0 \\
0 & \frac{\sqrt{3}}{2} & -\frac{\sqrt{3}}{2} & \frac{1}{2} & \frac{1}{2} & -1 \\
1 & -\frac{1}{2} & -\frac{1}{2} & -\frac{\sqrt{3}}{2} & \frac{\sqrt{3}}{2} & 0 \\
0 & -\frac{\sqrt{3}}{2} & \frac{\sqrt{3}}{2} & \frac{1}{2} & \frac{1}{2} & -1 \\
1 & 1 & 1 & 0 & 0 & 0 \\
0 & 0 & 0 & 1 & 1 & 1
\end{array}\right]\left[\begin{array}{c}
v_{1} \\
v_{2} \\
v_{3} \\
v_{4} \\
v_{5} \\
v_{6}
\end{array}\right]
$$

Due to geometry and machine characteristics, such as the rotating field and positioning of the coils, the voltage generated will be mapped in the $\left(\alpha_{1}, \beta_{1}\right)$ subspace, implying that only currents with belong to this subspace are capable of generating active power. However, it is important to control the currents in the subspace $\left(\alpha_{2}, \beta_{2}\right)$, even though they are not capable of generating active power, as these components can increase system losses.

\section{B. Input Current Transfer Function}

To determine the current transfer function, the converter is represented by its equivalent circuit model depicted in the Figure 2.

For the purpose of obtaining the current transfer function, the converter output voltage $\left(V_{o}\right)$ is considered constant and the converter legs are replaced with controlled voltages sources. The instantaneous value of this sources are determined by the output voltage and the duty cycle average value in a period $T_{S}$, as showed in (2), where $d_{i}(t)$ is the instantaneous periodical average value relative to the phase $i$.

$$
\left\langle v_{S i}(t)\right\rangle_{T_{s}}=V_{o}\left(d_{i}(t)-\frac{1}{2}\right), \quad i \in\{1,2,3,4,5,6\} .
$$

The equivalent circuit also explicits the common mode voltages between the source neutral points and the ground reference point $\left(V_{C M 1}\right.$ and $\left.V_{C M 2}\right)$. From the equivalent circuit is possible to obtain the equations described in the matrix form 


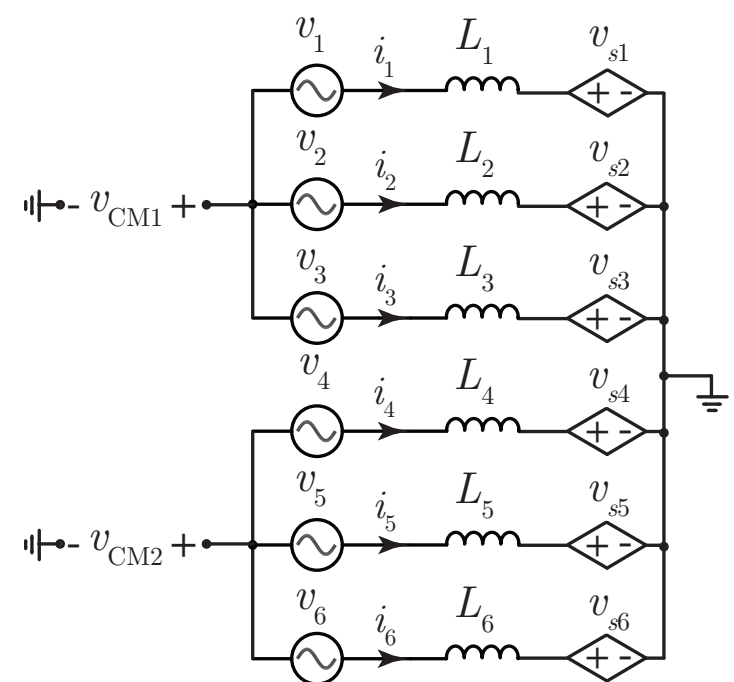

Fig. 2. Input equivalent circuit model of the Six-Phase Rectifier Topology.

as in (3), assuming an unique the inductance value of $L$ for all the inductors.

$$
\left[\begin{array}{l}
v_{1}(t) \\
v_{2}(t) \\
v_{3}(t) \\
v_{4}(t) \\
v_{5}(t) \\
v_{6}(t)
\end{array}\right]=L \frac{d}{d t}\left[\begin{array}{l}
i_{L 1}(t) \\
i_{L 2}(t) \\
i_{L 3}(t) \\
i_{L 4}(t) \\
i_{L 5}(t) \\
i_{L 6}(t)
\end{array}\right]+\left[\begin{array}{l}
v_{S 1}(t) \\
v_{S 2}(t) \\
v_{S 3}(t) \\
v_{S 4}(t) \\
v_{S 5}(t) \\
v_{S 6}(t)
\end{array}\right]+\left[\begin{array}{l}
v_{C M 1}(t) \\
v_{C M 1}(t) \\
v_{C M 1}(t) \\
v_{C M 2}(t) \\
v_{C M 2}(t) \\
v_{C M 2}(t)
\end{array}\right] .
$$

By substituting (2) into (3) and rewriting the equation in a compact form results in (4).

$$
\left[v_{i n}(t)\right]=L \frac{d}{d t}\left[i_{L}(t)\right]+v_{o}[d(t)]-\left[\frac{V_{o}}{2}\right]+\left[v_{C M}\right]
$$

Applying the stationary frame transformation (1) in (4) results in (5), which represents the system equations in $\alpha \beta$.

$$
\left[\begin{array}{l}
v_{\alpha 1}(t) \\
v_{\beta 1}(t) \\
v_{\alpha 2}(t) \\
v_{\beta 2}(t) \\
v_{01}(t) \\
v_{02}(t)
\end{array}\right]=L \frac{d}{d t}\left[\begin{array}{c}
i_{\alpha 1}(t) \\
i_{\beta 1}(t) \\
i_{\alpha 2}(t) \\
i_{\beta 2}(t) \\
i_{01}(t) \\
i_{02}(t)
\end{array}\right]+v_{o}\left[\begin{array}{l}
d_{\alpha 1}(t) \\
d_{\beta 1}(t) \\
d_{\alpha 2}(t) \\
d_{\beta 2}(t) \\
d_{01}(t) \\
d_{02}(t)
\end{array}\right]+\left[\begin{array}{c}
0 \\
0 \\
0 \\
0 \\
\sqrt{3}\left(v_{C M 1}-\frac{v_{o}}{2}\right) \\
\sqrt{3}\left(v_{C M 2}-\frac{v_{o}}{2}\right)
\end{array}\right]
$$

Equation (5) can also be represented by the equivalent circuits shown in Figure 3, which accurately represents the three-phase rectifier in $\alpha \beta$ coordinates. By inspection, it is possible to notice that the system is decoupled, i.,e, the relationship between inputs and outputs of the MIMO system can be expressed as six different SISO systems.

The transfer function of the system is then obtained by equating the equivalent circuit as in (6) and linearizing around an equilibrium point, resulting in (7).

$v_{x}(t)=L \cdot \frac{d}{d t} i_{x}(t)+v_{o} \cdot d_{x}(t), \quad x \in\left\{\alpha_{1}, \beta_{1}, \alpha_{2}, \beta_{2}\right\}$.

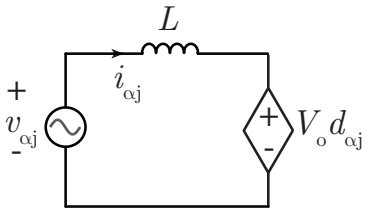

(a)

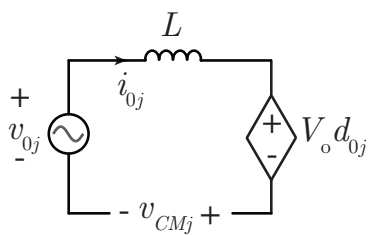

(c)

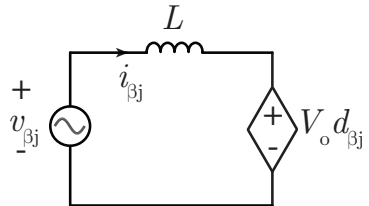

(b)

$j \in\{1,2\}$
Fig. 3. Input equivalent circuit in $\alpha \beta$ coordinates (a) $\alpha_{1}$ and $\alpha_{2}$ components circuit, (b) $\beta_{1}$ and $\beta_{2}$ components circuit and (c) $0_{1}$ and $\mathrm{O}_{2}$ components circuit.

$$
L \cdot \frac{d}{d t} \widetilde{i}_{x}=-V_{o} \widetilde{d}_{x}
$$

Therefore, each controllable SISO system can be described by the transfer function described in (8). Since the transfer function is the same for $\alpha 1, \beta 1, \alpha 2$ and $\beta 2$, the controller design can be replicated for the four current controls.

$$
\frac{\widetilde{i}_{x}(s)}{\widetilde{d}_{x}(s)}=-\frac{V_{o}}{s \cdot L}, \quad x \in\left\{\alpha_{1}, \beta_{1}, \alpha_{2}, \beta_{2}\right\} .
$$

Besides, the $0_{1}$ and $0_{2}$ components equivalent circuits are open, as it is assumed that there is no common mode current circulation, which implies that they cannot be controlled. This occurs due to the disconnection between the neutral points. and generates the common mode voltages displayed in the equivalent circuit in the Figure 2, similarly to a three-phase three-wire converter.

\section{Output Voltage Transfer Function}

The output voltage transfer function is obtained through the power equation of the converter as in (9).

$$
P_{\text {in }}=L \cdot i_{L} \frac{d}{d t} i_{L}+C_{o} \cdot v_{o} \frac{d}{d t} v_{o}+\frac{v_{o}^{2}}{R_{o}}+\text { Losses. }
$$

Disconsidering losses and representing the variables in the stationary reference frame the equation results in (10).

$$
v_{\alpha \beta} i_{\alpha \beta}=L \cdot i_{\alpha \beta} \frac{d}{d t} i_{\alpha \beta}+C_{o} \cdot v_{o} \frac{d}{d t} v_{o}+\frac{v_{o}^{2}}{R_{o}} .
$$

Applying the small signal model and the Laplace transformation in (10) results in (11).

$$
\widetilde{v_{o}}(s)\left(\frac{R_{o} C_{o} V_{o} s+2 V_{o}}{R_{o}}\right)=\widetilde{i_{\alpha \beta}}(s)\left(V_{\alpha \beta}-L I_{\alpha \beta}\right) .
$$

Hence the transfer function can be written as in (12).

$$
\frac{\widetilde{v}_{o}(s)}{\widetilde{i}_{\alpha \beta}(s)}=R_{o} \frac{V_{\alpha \beta}-L I_{\alpha \beta} s}{2+s C_{o} R_{o}} .
$$

By substituting the real project parameters in (12) results in (13), where the input current and voltage $\left(I_{\alpha \beta}\right.$ and $\left.V_{\alpha \beta}\right)$ in (13) are the peak values. 


$$
\frac{\widetilde{v}_{o}(s)}{\widetilde{i}_{\alpha \beta}(s)}=\frac{\frac{\sqrt{3} V_{p} R_{o}}{V_{o}}-\frac{L V_{o}}{\sqrt{3} V_{p}} s}{2+s C_{o} R_{o}} .
$$

It is possible to notice that the transfer function has a zero on the right half plane as occurs on the three-phase boost type rectifier or in the DC-DC boost converter. The nonminimal phase systems are, in general, harder to control in comparison to minimal phase systems, so it is important to take into account the zero in the voltage transfer function.

\section{STATIC ANALYSIS AND PROJECT EXAMPLE}

This section aims to present a criterium for the determination of the converter's parameters, as well as voltage and current stress in the semiconductors. The section also experimentally validates the presented models with a project example. The control block diagram of the cascaded control strategy is presented in Figure 4, which shows the sampled variables for the control and both voltage and current control loops.

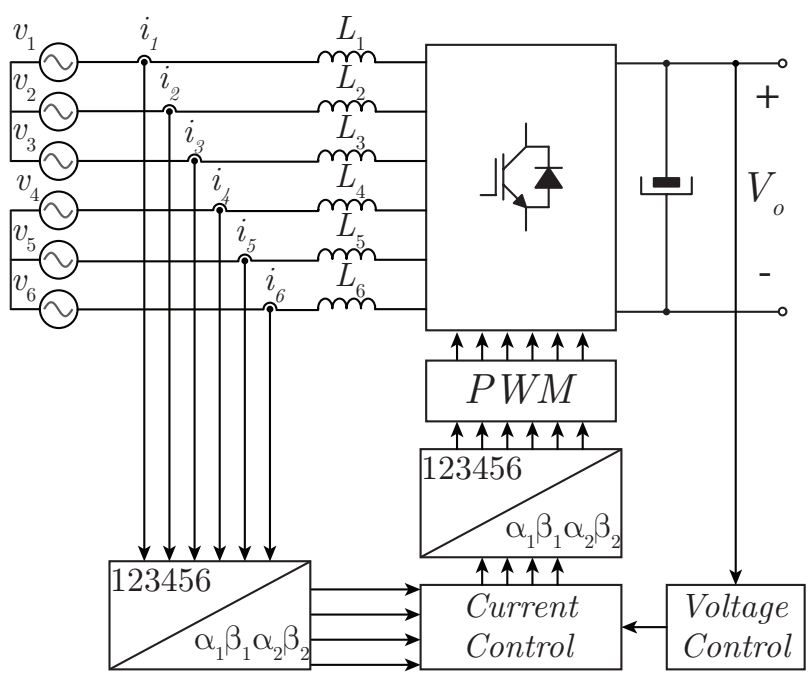

Fig. 4. Converter and control block diagram.

\section{A. Converter Parameters and Stress of the Semiconductor} Devices

The current ripple depends on the voltage on the input inductance, given by (14).

$$
\Delta I=\frac{1}{L} \int_{0}^{\Delta t} v_{L} d t
$$

The maximum ripple occurs at the input voltage peak, which for phase A occurs at $\omega t=\pi / 2$. Hence the inductance can be determined by equation (15).

$$
L=\frac{V_{p}}{\Delta I \cdot f_{s}}\left(\frac{1}{2}-\frac{V_{p}}{2 V_{o}}\right) .
$$

The DC bus capacitor can be determined by the hold-up time criteria. Since the output power is constant, similar to any poly-phase system, the dc bus capacitance is given by (16).

$$
C_{o}=\frac{P_{o} \cdot t_{H U}}{V_{o}^{2} \Delta V_{\%}} .
$$

The voltage stress in the switches is given by the DC bus voltage, given by (17).

$$
V_{\text {Smax }}=V_{o} .
$$

Diode average and RMS current values are determined by (18) and (19), respectively.

$$
\begin{gathered}
I_{\text {Davg }}=\frac{P_{o}\left(2 V_{o}+\pi V_{p}\right)}{12 \pi V_{p} V_{o}} . \\
I_{\text {Drms }}=\frac{P_{o}}{6 V_{p}} \sqrt{\frac{16 V_{p}+3 \pi V_{o}}{6 \pi V_{o}} .}
\end{gathered}
$$

The semiconductor devices average and RMS are described by (20) and (21), respectively.

$$
I_{\text {Savg }}=\frac{P_{o}\left(2 V_{o}-\pi V_{p}\right)}{12 \pi V_{p} V_{o}} .
$$

Switch RMS current:

$$
I_{\text {Srms }}=\frac{P_{o}}{6 V_{p}} \sqrt{\frac{3 \pi V_{o}-16 V_{p}}{6 \pi V_{o}}} .
$$

\section{B. Converter Specifications}

The parameters obtained for the converter design from the previously obtained equations are summarized in Table I.

\section{TABLE I}

Converter Parameters in Simulation

\begin{tabular}{cc}
\hline Parameter & Value \\
\hline Voltage Source frequency & $f_{g}=60 \mathrm{~Hz}$ \\
\hline Switching frequency & $f_{s}=9990 \mathrm{~Hz}$ \\
\hline AC Voltage input & $V_{\text {in }}=220 \mathrm{~V}_{R M S}$ \\
\hline DC Voltage output & $V_{o}=800 \mathrm{~V}$ \\
\hline Output Power & $P_{0}=12 \mathrm{~kW}$ \\
\hline Input Inductance & $L_{\text {in }}=2 \mathrm{mH}$ \\
\hline Output Capacitance & $C_{0}=4700 \mu \mathrm{F}$ \\
\hline Load Equivalent Resistance & $R_{0}=53 \Omega$ \\
\hline
\end{tabular}

For the given design specification, the following design constraints were adopted: for the inductance, a maximum ripple of $20 \%$ at the peak current was considered, while a hold up time of $33 \mathrm{~ms}$ and a voltage ripple less than $10 \%(\Delta V \%)$ were considered the capacitance design.

\section{Model Validation}

To validate the converter model, the time domain response of the converter and the linearized model were compared while applying an input disturbance. Figure 5 shows the response for a duty cycle disturbance, which demonstrates the superposition of both responses.

Figure 6 demonstrates the response of the output voltage for a current step. A small difference between the transfer function and the circuit response was observed, especially in the static gain. Most of the difference is due to the inductance resistance and a minor difference due to non-ideality of the semiconductors. However, the difference is very small and the transfer function is a representative model, which can be employed in the control design. 


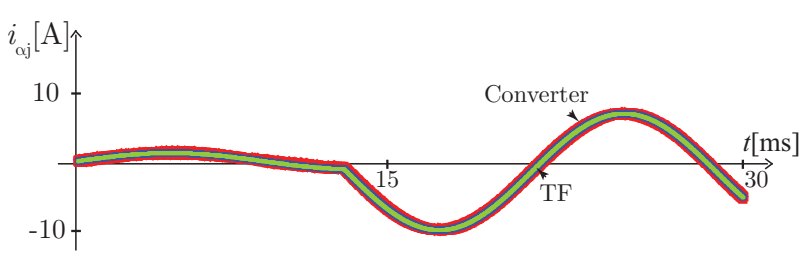

Fig. 5. Validation of the proposed transfer function of the input current per duty cycle (8): Comparison of the power converter versus equation 8 during a step on duty cycle.

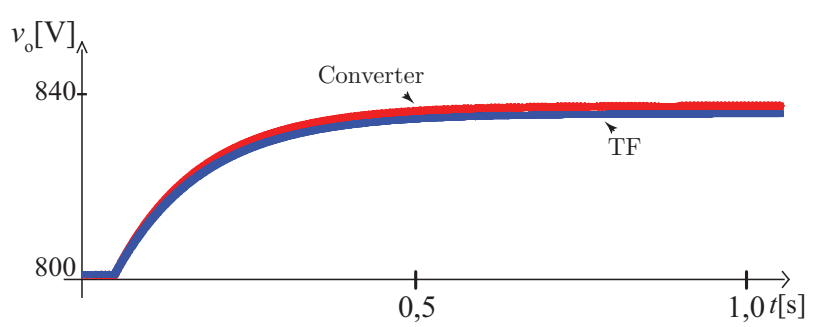

Fig. 6. Validation of the proposed transfer function of the output voltage per input current (13): Comparison of the power converter versus equation 13 during a step on the input current.

\section{Control Design}

The control strategy consists in two cascaded control loops, a faster inner loop that controls the input currents and a slower loop which is responsible for controlling the DC link voltage. A block diagram of the proposed control strategy is presented in Figure 7, where the variables indicated with an asterisk are the references for the control loops.

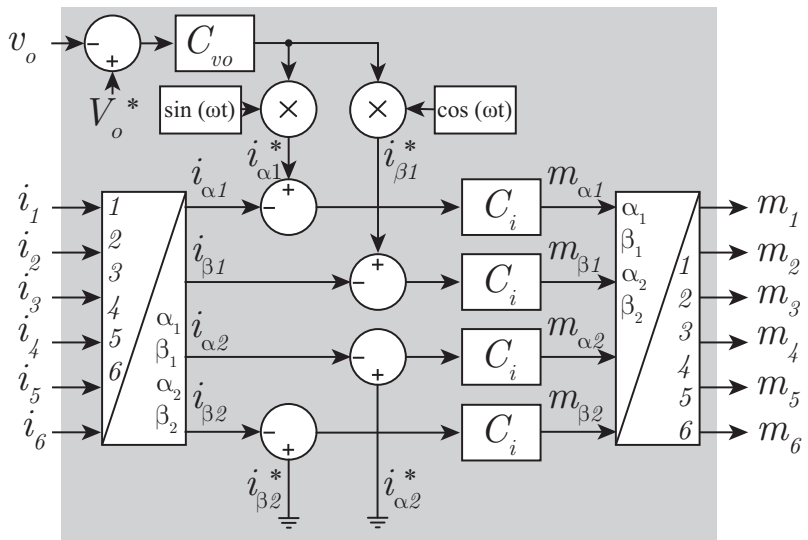

Fig. 7. Stationary reference frame control strategy block diagram for the six-phase PWM active rectifier.

The voltage controller input is the DC voltage error and its output controls the $\alpha \beta$ currents amplitude. The voltage controller output is multiplied by sine waves generating the $\alpha_{1} \beta_{1}$ currents reference, while the $\alpha_{2} \beta_{2}$ currents reference are always.

The input currents (in $\alpha \beta$ coordinates) are subtracted from the currents references, resulting in the currents error, which is applied to the current controllers generating the duty cycle in $\alpha \beta$ reference frame. On applying the inverse transformation on it, the duty cycle for each arm is obtained.

For a proper closed loop operation, two compensator were designed to control the input current and the load bus voltage. As previously discussed, the current and voltage transfer functions used for the controller project are presented in (8) and (13), respectively.

The chosen compensator was a proportional integrator (PI) controller, projected to reject step disturbances, as presented in (22).

$$
P I(s)=K_{P I} \frac{1+s T_{P I}}{s T_{P I}} .
$$

To design the PI controller, the root locus method was employed, with the parameters arbitrated for the closed loop response for the current loop a damping higher than 0.7 $(\zeta>0.7)$ and a natural frequency lower than $\frac{4 \pi}{10 T_{s}}\left(\omega_{n}<\frac{4 \pi}{10 T_{s}}\right)$. The criteria for the voltage loop was $\zeta>0.9$ and $\omega_{n}<$ $\frac{4 \pi}{20 T_{s}}$ obtaining the current and voltage controllers respectively shown in (23) and (24).

$$
\begin{aligned}
C_{I}(s) & =1.1 \frac{1+10^{-4}}{s 10^{-4}} . \\
C_{V}(s) & =28 \frac{1+6 \cdot 10^{-3}}{s 6 \cdot 10^{-3}} .
\end{aligned}
$$

\section{EXPERIMENTAL RESULTS}

In this section the modelling and the structure are validated by a prototype, presented in Figure 8 . The parameters presented in the Table I were used for the project of the converter.

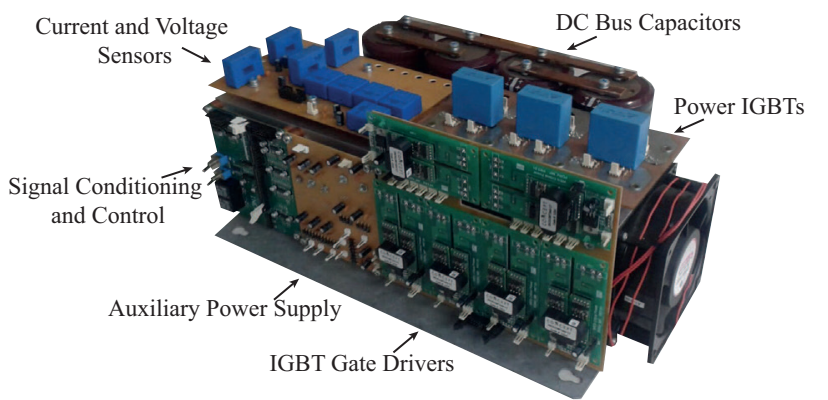

Fig. 8. Six-phase voltage converter prototype.

\section{A. Converter Prototype and Experimental Results}

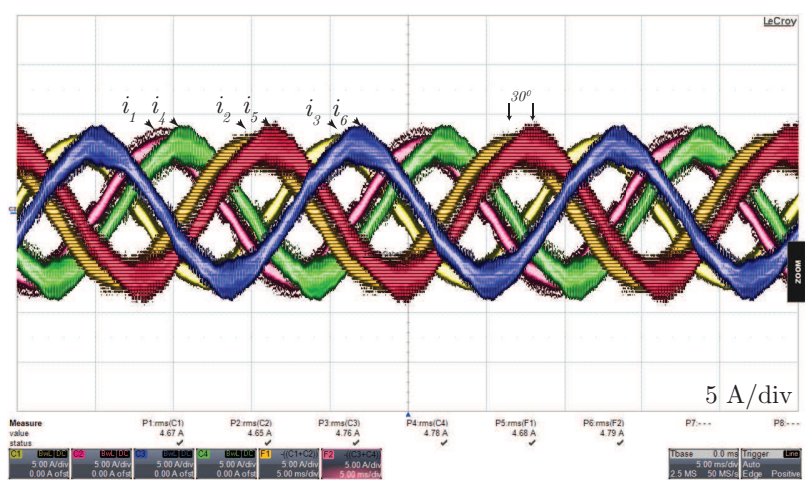

Fig. 9. Six-phase input voltages and currents of the converter operating in steady state.

The operation of six-phase rectifier using the control strategy proposed is experimentally verified and the results are presented as the following. Figure 9 shows the six-phase inductor currents which are drawn from source, the currents are approximate to a sinus wave indicating a high power factor. 


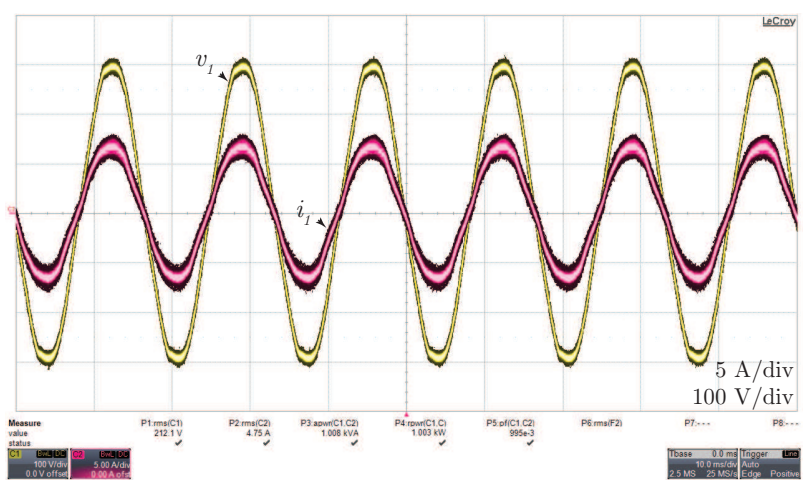

Fig. 10. Input voltage and current for phase 1 of the converter operating in steady state.

Figure 10 shows the input voltage and current for the phase 1. In this case the converter operates with $50 \%$ of the nominal power and presents a power factor of 0.995 and a $T H D_{i}=$ $8.96 \%$. Most of the harmonic distortion in the current is due to harmonic components around the switching frequency.

The dynamic response for a load step of $50 \%$ of the nominal power is displayed in the Figure 11, the output voltage is regulated and the control provides an adequate dynamic response, in accord to the control project criteria. The current loop present a fast transient having a settling time of circa 2 $\mathrm{ms}$, while the voltage loop is slower having a settling time of proximately $30 \mathrm{~ms}$.

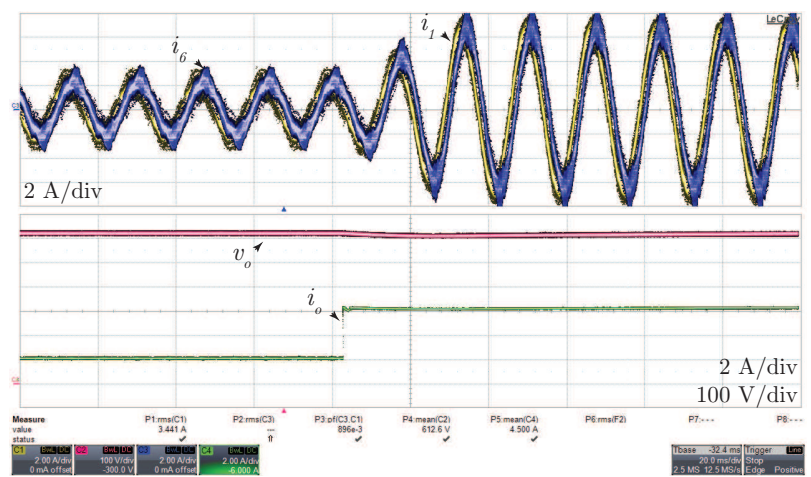

Fig. 11. Input current and output voltage dynamic response for a load step of $50 \%$.

If compared with the twelve pulse diode rectifier, which is the commercial solution for power rectification in poly phase wind power generation [15], the proposed converter presents a regulated voltage output with higher voltage level, since it is a boost type converter. Besides it presents a reduced harmonic distortion in the currents drained from the generator, the experimental prototype currents presented a $T H D_{i}=$ $8.96 \%$, while twelve pulse diode rectifier current THD have typical values circa $30 \%$. The proposed PWM rectifier reduces significantly the current lower harmonic components, emphasizing the $12 n \pm 1$ harmonics, which cause oscillating torque in the machine and the $12 n \pm 5$, that have no influence in the torque, however contribute to the system losses.

\section{CONCLUSION}

This paper proposed a six-phase two-level voltage source rectifier, its model and a control scheme in stationary frame reference. The presented converter model is a transfer function aiming the employ of classical control technics. The model was validated by simulation and it presented suitable results.

A stationary frame control strategy for the rectifier was proposed and validated through simulation. The control strategy demonstrated appropriated results, providing a regulated output voltage, an input current with reduced harmonic distortion and a high power factor. The proposed topology may be employed in six-phase wind generation systems when a lower current distortion or a regulated output is desired.

The main contribution of this paper is the proposal of an active rectifier for the six-phase system presenting the modelling and a control strategy for the converter as a single system, and not as a dual three-phase system, providing a better control and operation of the system, while focusing on technical aspects and the operation of the power converter.

\section{ACKNOWLEDGEMENTS}

The authors would like to thank Prof. Telles B. Lazzarin for the review of the manuscript and for the technical discussions.

\section{REFERENCES}

[1] C. Qiao, K. M. Smedley, "A general three-phase PFC controller for rectifiers with a parallel-connected dual boost topology", IEEE Transactions on Power Electronics, vol. 17, no. 6, pp. 925-934, Nov 2002, doi:10.1109/TPEL.2002.805582.

[2] A. A. Badin, I. Barbi, "High power factor three-phase rectifier with two interleaved singlephase buck rectifier", in XI Brazilian Power Electronics Conference, pp. 183-188, Sept 2011, doi:10.1109/COBEP.2011.6085194.

[3] J. C. Salmon, "Operating a three-phase diode rectifier with a low-input current distortion using a seriesconnected dual boost converter", IEEE Transactions on Power Electronics, vol. 11, no. 4, pp. 592-603, July 1996, doi:10.1109/63.506125.

[4] Y. Luo, Z. Chen, Y. Zhu, Y. Qiu, “Three-phase rectifier with near-sinusoidal input currents and capacitors parallel connected with the upper diodes", in 2009 IEEE 6th International Power Electronics and Motion Control Conference, pp. 1697-1702, May 2009, doi: 10.1109/IPEMC.2009.5157665.

[5] R. L. Alves, I. Barbi, "Analysis and Implementation of a Hybrid High-Power-Factor Three-Phase Unidirectional Rectifier", IEEE Transactions on Power Electronics, vol. 24, no. 3, pp. 632-640, March 2009, doi:10.1109/TPEL.2008.2010219.

[6] T. B. Soeiro, J. W. Kolar, "Analysis of High-Efficiency Three-Phase Two- and Three-Level Unidirectional Hybrid Rectifiers", IEEE Transactions on Industrial Electronics, vol. 60, no. 9, pp. 3589-3601, Sept 2013, doi:10.1109/TIE.2012.2205358.

[7] B. Yin, R. Oruganti, S. K. Panda, A. K. S. Bhat, "Control of a Three-Phase PWM Rectifier Based on a Dual Single-Input Single-Output Linear Model", in 2005 International Conference on Power Electronics 
and Drives Systems, vol. 1, pp. 456-461, Nov 2005, doi:10.1109/PEDS.2005.1619730.

[8] B. Yin, R. Oruganti, S. K. Panda, A. K. S. Bhat, "Experimental verification of a dual singleinput single-output model of a three-phase boost-type PWM rectifier", in 31st Annual Conference of IEEE Industrial Electronics Society, 2005. IECON 2005., pp. 6 pp.-, Nov 2005, doi:10.1109/IECON.2005.1569046.

[9] H. Tao, Z. Zheng, "Study of Three-Phase PWM Rectifier Based on Dual-Mode Control", in 2010 International Conference on E-Product E-Service and E-Entertainment, pp. 1-4, Nov 2010, doi: 10.1109/ICEEE.2010.5660156.

[10] H. Ye, A. Emadi, "A Six-Phase Current Reconstruction Scheme for Dual Traction Inverters in Hybrid Electric Vehicles With a Single DC-Link Current Sensor", IEEE Transactions on Vehicular Technology, vol. 63, no. 7, pp. 3085-3093, Sept 2014, doi: 10.1109/TVT.2014.2305637.

[11] M. A. Abbas, R. Christen, T. M. Jahns, "Six-Phase Voltage Source Inverter Driven Induction Motor", IEEE Transactions on Industry Applications, vol. IA-20, no. 5, pp. 1251-1259, Sept 1984, doi: 10.1109/TIA.1984.4504591.

[12] E. Levi, M. Jones, S. N. Vukosavic, H. A. Toliyat, "Steady-State Modeling of Series-Connected Five-Phase and Six-Phase Two-Motor Drives", IEEE Transactions on Industry Applications, vol. 44, no. 5, pp. 1559-1568, Sept 2008, doi: 10.1109/TIA.2008.2002268.

[13] A. A. Nahome, R. Zaimeddine, B. Liu, T. Undeland, "Vector control of direct drive six phase permanent magnet synchronous generators", in 2011 IEEE Trondheim PowerTech, pp. 1-7, June 2011, doi: 10.1109/PTC.2011.6019330.

[14] V. Yaramasu, B. Wu, P. C. Sen, S. Kouro, M. Narimani, "High-power wind energy conversion systems: Stateof-the-art and emerging technologies", Proceedings of the IEEE, vol. 103, no. 5, pp. 740-788, May 2015, doi: 10.1109/JPROC.2014.2378692.

[15] X. Xin, L. Hui, "Research on multiple boost converter based on MW-level wind energy conversion system", in 2005 International Conference on Electrical Machines and Systems, vol. 2, pp. 1046-1049 Vol. 2, Sept 2005, doi:10.1109/ICEMS.2005.202706.

[16] N. Rathika, A. S. Kumar, P. Sivakumar, R. S, "Analysis and control of multiphase synchronous generator for renewable energy generation", in 2014 International Conference on Advances in Electrical Engineering (ICAEE), pp. 1-6, Jan 2014, doi: 10.1109/ICAEE.2014.6838551.

[17] I. Abdelsalam, G. P. Adam, D. Holliday, B. W. Williams, "Assessment of a wind energy conversion system based on a six-phase permanent magnet synchronous generator with a twelve-pulse PWM current source converter", in 2013 IEEE ECCE Asia Downunder, pp. 849-854, June 2013, doi: 10.1109/ECCE-Asia.2013.6579203.

[18] E. Miliani, M. Y. Ayad, D. Depernet, J. M. Kauffmann, "Experimental Analysis of a Six Phase Permanent
Magnet Synchronous Generator in a Variable Speed Constant Frequency Generating System", in APEC 07 - Twenty-Second Annual IEEE Applied Power Electronics Conference and Exposition, pp. 17271732, Feb 2007, doi:10.1109/APEX.2007.357752.

[19] K. Zhang, H. M. Kojabadi, P. Z. Wang, L. Chang, "Modeling of a Converter-Connected Six-Phase Permanent Magnet Synchronous Generator", in 2005 International Conference on Power Electronics and Drives Systems, vol. 2, pp. 1096-1100, Nov 2005, doi:10.1109/PEDS.2005.1619851.

[20] C. A. Arbugeri, T. B. Lazzarin, S. A. Mussa, "Sixphase active PWM rectifier with stationary frame reference control", in 2017 IEEE 26th International Symposium on Industrial Electronics (ISIE), pp. 856860, June 2017, doi:10.1109/ISIE.2017.8001358.

[21] W. C. Duesterhoeft, M. W. Schulz, E. Clarke, "Determination of Instantaneous Currents and Voltages by Means of Alpha, Beta, and Zero Components", Transactions of the American Institute of Electrical Engineers, vol. 70, no. 2, pp. 1248-1255, July 1951, doi:10.1109/T-AIEE.1951.5060554.

[22] J. L. Willems, "Generalized Clarke Components for Polyphase Networks", IEEE Transactions on Education, vol. 12, no. 1, pp. 69-71, March 1969, doi: 10.1109/TE.1969.4320448.

[23] R. Bojoi, M. Lazzari, F. Profumo, A. Tenconi, "Digital field oriented control for dual three-phase induction motor drives", in Conference Record of the 2002 IEEE Industry Applications Conference. 37th IAS Annual Meeting (Cat. No.02CH37344), vol. 2, pp. 818-825 vol.2, Oct 2002, doi:10.1109/IAS.2002.1042653.

Cesar Augusto Arbugeri Nascido em Joaçaba, Santa Catarina, Brasil, em 1990. Recebeu o grau de Engenheiro eletricista e mestre pela Universidade Federal de Santa Catarina (UFSC), Florianópolis, Brasil, em 2014 e 2016, respectivamente. Atualmente é doutorando no programa de pos-graduação em Engenharia Elétrica da Universidade Federal de Santa Catarina (UFSC) e pesquisador no Instituto de Eletrônica de Potôncia (INEP).

Samir Ahmad Mussa Recebeu o grau de Engenheiro eletricista pela Universidade Federal de Santa Maria em 1988, recebeu grau de Mestre e de Doutor pela Universidade Federal de Santa Catarina em 1994 e 2003 respectivamente e PósDoutorado no Imperial College London, Inglaterra entre 2015 e 2016. Possui graduação em Matemática e habilitação em Física pela Unifra, Santa Maria-RS (1986). Atualmente ocupa o cargo de professor no Departamento de Engenharia Elétrica e Eletrônica (EEL) da Universidade Federal de Santa Catarina (UFSC) e pesquisador no Instituto de Eletrônica de Potência (INEP). Seus interesses de pesquisa incluem retificadores $\mathrm{PFC}$, processamento de sinais digitais e controle aplicado em eletrônica de potência, sistemas baseados em DSP, FPGA e microprocessadores. Dr. Mussa é membro da Sociedade Brasileira de Eletrônica de Potência (SOBRAEP) e do IEEE Society. 